\title{
0 processo de alcoolização entre os Tenharim das aldeias do rio Marmelos, AM, Brasil ${ }^{*}$
}

Priscilla Perez da Silva Pereira ${ }^{1}$

Ari Miguel Teixeira Ott²

PEREIRA, P.P.S.; OTT, A.M.T. The process of development of alcoholism among the Tenharim people in villages along the Marmelos river, state of Amazonas. Interface Comunic., Saude, Educ., v.16, n.43, p.957-66, out./dez. 2012.

The aim of this paper was to analyze the process of development of alcoholism in villages along the Marmelos river using an anthropological approach. The way in which the Tenharim people drink is related mainly to a rite of passage for males, with rules that are well defined by the families, with protection and control mechanisms. It could be seen that development of alcoholism has been discussed by these indigenous people, but with differences regarding whether it is defined as a problem. This breaks up the actions implemented against the development of problematic alcoholism. The position of liminality taken by those who consume alcohol demonstrates that there is a need for social fortification of the community.

Keywords: Health and Society. Development of alcoholism. Rite of Passage. Tenharim. Amazonas.
O objetivo deste trabalho foi analisar esse processo de alcoolização nas aldeias do Marmelos utilizando o enfoque antropológico. A forma como os Tenharim bebem está relacionada, sobretudo, a um rito de passagem masculino e com regras bem definidas pelas famílias, com seus mecanismos de proteção e controle. Foi possível notar que a alcoolização vem sendo discutida pelos indígenas, mas, com diferenças quanto à definição como um problema ou não, fato que fragmenta as ações desenvolvidas contra a alcoolização problemática. A posição de liminaridade assumida pelos que consomem álcool demonstra a necessidade de fortalecimento social da comunidade.

Palavras-chave: Saúde e Sociedade. Alcoolização. Rito de Passagem. Tenharim. Amazonas.

\footnotetext{
Elaborado com base em Pereira (2010); pesquisa aprovada pelo

Comitê de Ética em Pesquisa da Universidade Federal de Rondônia e pelo Conselho Nacional de Ética e Pesquisa, sob o registro CONEP 15510, atendendo à Resolução 196/96 do Conselho Nacional de Saúde. Financiado pelo Ministério da Saúde/ DECIT/CNPq (Proc 402532/2008-2

${ }^{1}$ Departamento de Enfermagem Universidade Federal de Rondônia. Campus, BR 364, KM 9,5. Porto Velho, RO, Brasil. 78.900-000.

d.pri@bol.com.br

2 Departamento de Ciências Sociais Universidade Federal de Rondônia.
} 


\section{Introdução}

Os Tenharim pertencem a um grupo maior, que se autodenomina Kagwahiva, povo indígena Tupi que teria migrado, no século XIX, do Alto Tapajós para o oeste do Amazonas, devido a conflitos com outros grupos indígenas. As Terras Indígenas (TI) Tenharim estão divididas em três grandes reservas, com um total de 790 indígenas: do Marmelos, do Igarapé Preto e do Sepoti. A população do Marmelos, com 272 indígenas, está distribuída em quatro aldeias. Organizam-se conforme um sistema de metades exogâmicas, que recebem nomes de aves. Essas metades são: Mutum-Nanguera e Kwandu-Tarave.

As informações prévias de uma das lideranças é de que a alcoolização entre os Tenharim, em alguns momentos e para alguns, havia tomado proporções consideradas por eles como negativas para a comunidade indígena. Assim, empunha-se o desafio de conhecer as causas e motivações da alcoolização, considerando esse processo como:

[...] o conjunto de funções e conseqüências positivas e negativas que cumpre a ingesta de álcool para conjuntos sociais estratificados, e não apenas o estudo dos alcoólicos dependentes, nem os excessivos, nem os moderados, nem os abstêmios, mas sim o processo que inclui a todos e que evita considerar o problema em termos de saúde e/ou enfermidade mental. (Menendez, 1982, p.63)

Portanto, o objetivo deste artigo é a descrição do processo de alcoolização, sendo necessário conhecer o que eles bebem, como e quando. Apenas definir a forma do consumo não fornece subsídios para se compreender o processo como um ato social. É necessário abordar os grupos que fazem parte do universo dessa comunidade indígena e são capazes de valorizar o ato de beber ou não beber, considerando, assim, também o contexto social que envolve os moradores da aldeia Marmelos e do Município de Humaitá.

A abordagem qualitativa, com um enfoque antropológico, demonstrou ser o método mais adequado para a descrição do processo de alcoolização entre os Tenharim. A pesquisa de campo foi realizada no período de julho de 2009 a janeiro de 2010, perfazendo um total de 21 dias. Os sujeitos ouvidos na cidade de Humaitá foram: responsáveis pela Fundação Nacional do Índio (FUNAI); Fundação Nacional de Saúde (FUNASA); Casa do Índio (CASAI); representantes do Conselho Distrital de Saúde Indígena; Secretaria de Saúde; donos de bares e funcionários dos bares e hotéis mais frequentados pelos indígenas; e pessoas da cidade de Humaitá que estavam, no momento da coleta de dados, na praça principal, bares e restaurantes da região ao redor da rodoviária.

Nas aldeias, foram entrevistadas todas as lideranças do Marmelos (cacique, vice-cacique, Agente Indígena de Saúde - AIS, Agente Indígena de Saneamento - AISAN, professores, presidente do conselho local de saúde indígena e conselheiros); idosos; representantes das famílias (homens e mulheres casados); e os jovens.

Foram utilizadas dez perguntas disparadoras, sendo registradas as respostas em relatórios, dando ênfase às opiniões, comentários e frases que foram analisadas por meio da técnica de paráfrase das ciências sociais - hermenêutica.

A pesquisa foi aprovada pelo Comitê de Ética em Pesquisa da Universidade Federal de Rondônia e pelo Conselho Nacional de Ética e Pesquisa, sob o registro CONEP 15510, atendendo à Resolução 196/ 96 do Conselho Nacional de Saúde.

\section{A Transamazônica e a contribuição para a mudança no estilo de vida dos Tenharim}

A cultura Tenharim, como se apresenta na atualidade, é intrínseca à história de desenvolvimento da Região Amazônica. O contato marcado por conflitos que haviam se iniciado no século XIX, sobretudo devido ao processo de extrativismo, completou-se efetivamente na década de 1970, com a abertura do garimpo Paranapanema e da estrada Transamazônica (Peggion, 2005). 
A Transamazônica, considerada como a "estrada brasileira para o etnogenocídio" (Davis, 1978, p.7), foi o projeto de desenvolvimento que interferiu de maneira direta nas aldeias Tenharim do Marmelos. Os contatos decorrentes da mineradora e da estrada intensificaram-se e levaram a uma significativa modificação estrutural da aldeia, especialmente na forma de subsistência da comunidade.

Os índios Tenharim que viviam na aldeia Nhande'uhu, ao longo do rio Marmelos, se deslocaram para as margens do traçado da Transamazônica, na tentativa de frearem as ações da construção da estrada. Sem muitas opções de sustento e infraestrutura, os índios acabaram aceitando as ações paternalistas da FUNAI: casas, mudança do local das roças, a introdução de novos alimentos manufaturados e de objetos, como roupas (Silva, 2006; Peggion, 2005; Sampaio, 1997).

A Transamazônica era um ingrediente importante do milagre econômico e seria construída ao preço que fosse necessário. Afinal, o curso de desenvolvimento da Amazônia atenderia interesses políticos e econômicos, e não seriam os obstáculos naturais, incluindo aí os índios, que inviabilizariam o "desenvolvimento". A exploração da Amazônia visava atender os interesses, sobretudo, de multinacionais e grandes fazendeiros beneficiados pelos incentivos fiscais e tributários da Superintendência de Desenvolvimento da Amazônia (SUDAM) (Davis, 1978).

\section{O uso de bebidas industrializadas pelos Tenharim}

Na maioria das culturas indígenas, as bebidas fermentadas são consumidas como alimento ou de maneira sagrada, podendo ou não causar desconfortos físicos ou sociais entre os membros da comunidade indígena. A função da bebida fermentada é determinada pelo teor de álcool, podendo ser classificada como fraca ou forte (Souza, Oliveira, Kohatsu, 2003).

Na revisão de literatura, foram encontradas três referências aos Tenharim e o uso de cauim - kawy (forma como os sujeitos da pesquisa chamam as bebidas fermentadas produzidas artesanalmente). A primeira, em 1924, refere-se ao consumo da bebida como um ato sem importância entre os Kagwahiva (Nimuendajú, 1924). A segunda, apontada por um funcionário do Serviço de Proteção ao Índio (SPI), em 1926, descreve o uso do cauim após as guerras, em rituais chamados de festa da quebra da cabeça do inimigo, nos quais o objetivo de seu consumo não era embebedar (Freitas, 1926). E a terceira referência era o mito de Bahira - o personagem central da mitologia Kagwahiva, quando, em uma das festas realizadas por Bahira, o cauim de milho foi oferecido como alimento (Silva, 2006).

Além das referências anteriores, de acordo com as falas dos sujeitos, não há indícios do uso do cauim com fins de cauinagem, ou seja, a utilização de cauim azedo em grande quantidade durante comemorações (Peggion, 2005; Lima 1996). A bebida fermentada, produzida artesanalmente, e não utilizada para fins de embriaguez não é exclusividade do povo indígena Tenharim. Entre grande parte dos grupos de língua Jê e os índios do alto Xingu, encontram-se exceções para a fabricação e o uso do cauim, como, por exemplo, os Matis (povo indígena da Amazônia Central). Entre eles, o cauim era feito de macaxeira, quase sem teor alcoólico, e era utilizado cotidianamente como alimento (Souza, Garnelo, 2007).

Portanto, não houve uma substituição do cauim pela bebida alcoólica industrializada, como encontrado em outras aldeias indígenas. O contato com as bebidas alcoólicas industrializadas foi em função da construção da Transamazônica. Construção esta que proporcionou, aos Tenharim, acesso às bebidas industrializadas e ao dinheiro para compra de produtos variados, entre eles, o álcool.

A utilização de cachaça pelos Tenharim foi realizada inicialmente sem normas quanto à idade, sexo, motivo ou forma de utilização. Eles a utilizavam como quem descobre uma fonte poderosa para sensações de relaxamento, desinibição e socialização. Porém, alguns apenas experimentaram e, devido ao gosto que não era agradável, não mais consumiram.

O grande fluxo de pessoas que passava na estrada e a presença de transações comerciais próximas aos acampamentos dos trabalhadores facilitavam o acesso, sobretudo, à cachaça.

Mas, o ato de beber não permaneceu de maneira descontrolada. Inicialmente, devido à interferência da FUNAI e, posteriormente, com a definição de uma disciplina tradicional pelos próprios membros da comunidade indígena, várias normas foram instituídas na tentativa de controlar ou amenizar os problemas referenciados ao processo de alcoolização. 


\section{A alcoolização entre os Tenharim}

A forma de beber não pode ser considerada universal. Não é possível fazer uma avaliação do uso de bebidas alcoólicas da mesma maneira em todas as populações indígenas. É necessário considerar: o contexto social, ou seja, suas normas de conduta, a forma de punição, as dimensões de positivo e negativo dessa comunidade (Souza, Garnelo, 2007). Para isso, é importante uma contextualização do uso do álcool na cultura indígena até a atualidade.

\section{Com quem bebem}

O consumo das bebidas alcoólicas ocorre na aldeia ou na cidade. Em sua maioria, é de forma coletiva, ou seja, em pequenos grupos de homens de uma mesma faixa etária ou posição social (jovens, liderança, homens adultos), independente da metade exogâmica (Mutum ou Taravé) ou grau de parentesco ao qual o indivíduo pertence.

Não há relatos de que mulheres utilizem álcool, pelo contrário, o seu uso está restrito aos homens, que encontram maior liberdade de acesso às bebidas e permissão consensual para o seu consumo.

A ingestão de álcool entre os indígenas sempre ocorre de maneira socializada - grupal -, fato este que contribui para o reforço da alcoolização coletiva. Esse fortalecimento numa relação coletiva contribui para que seja utilizado mais álcool, levando, assim, a um estado de exclusão desse pequeno grupo do restante da comunidade indígena (Sztutman, 2008; Acioli, 2002). Este fato pode ser constatado entre os rapazes do Marmelos, que andam juntos e utilizam as bebidas especialmente à noite, quando as famílias estão em suas casas.

Fora do ambiente da aldeia, o uso de bebidas também se configura de maneira coletiva. Junto a não-indígenas ou outros indígenas, o uso do álcool está associado ao divertimento, sobretudo após o trabalho ou estudo - "eu já bebi muito, na cidade a gente faz pra se entrosar melhor e na aldeia é só de farra mesmo" (Jovem Tenharim, 17 anos).

Os adultos que se encontravam em uma posição de autônomos parecem utilizar o álcool como forma de comprovar essa autonomia, e os jovens a utilizavam, em meio aos não-índios, como forma de autoafirmação e aproximação. Mecanismo apontado, por Dal Poz (2003), como mobilidade social, quando o indivíduo se despoja de costumes do seu grupo étnico para tornar-se membro de outro grupo étnico.

Aquele que bebe sozinho e em qualquer momento do dia é considerado, pela comunidade, como doente. Essa individualização no consumo das bebidas e a intensificação do contato com os não-índios, por meio da permanência nos centros urbanos, contribui para que os indígenas assumam um padrão de individualismo (Coloma, 2001). A substituição de um padrão coletivo para individual estabelece uma mudança sociocultural que interfere nos campos da política, economia e cultura.

\section{Quando bebem}

O consumo de bebidas alcoólicas ocorre, sobretudo, em dias de eventos comemorativos ou jogos esportivos, aos finais de semana, à noite ou nas idas à cidade.

Nos dias rotineiros marcados pelas atividades, como estudo, trabalhos na casa de farinha, agricultura ou caça, o uso de bebidas se dá com menor intensidade e, geralmente, após o desligamento da energia elétrica. Ocorre em pequenos grupos de jovens enquanto escutam músicas em aparelhos sonoros movidos por energia proveniente de baterias.

\section{Onde bebem}

O consumo ocorre em um determinado espaço que, dependendo da situação, pode ter seus limites ampliados ou diminuídos. As aldeias se configuram em uma região central: escola, campo de futebol, casa de farinha; e área periférica: os rios, roças e mata. Para manter a discrição no ato de beber durante as festas, no período do dia, os índios consomem o álcool embaixo de árvores afastadas, na beira do rio, 
em regiões próprias de banho, e em cantos da estrada. Mas, à noite, quando a música já está tocando e a dança iniciada, todos se aproximam do barracão de reuniões. Os que já estão alcoolizados permanecem em grupos, sendo possível observar comportamentos extravagantes, incomuns aos Tenharim em dias normais. Quanto mais a noite adentra, mais fácil é encontrar indígenas utilizando as bebidas alcoólicas, de maneira mais exposta e explícita.

Diferente dos dias de festas, em dias de semana, o consumo é discreto - o que tornava o ato praticamente imperceptível. Ocorria entre grupos de jovens, durante a noite e mais próximo às áreas das casas, sobretudo na área do campo de futebol e do pedágio.

\section{O que bebem}

As bebidas alcoólicas utilizadas pelos Tenharim são escolhidas conforme a facilidade no acesso e conservação. Na aldeia, a bebida mais utilizada é a cachaça, devido à possibilidade de consumo sem refrigeração. Nas cidades, além da cachaça, outra bebida consumida é a cerveja.

\section{Acesso às bebidas}

Existem alguns fatores facilitadores para o consumo de bebidas alcoólicas pelos indígenas. Entre eles, os mais importantes são: a proximidade das aldeias de pontos de venda e o baixo custo da bebida.

Os fatos determinantes para o acesso às bebidas pelos Tenharim foram: a criação de uma vila chamada 180, que está a cinquenta km do Marmelos, e a aquisição de motos - meio de transporte rápido e barato que proporciona acesso aos pontos de comércio dessa vila e ao longo da Transamazônica.

\section{A idade para o consumo e a relação com o rito de passagem masculino}

Anteriormente, os meninos tornavam-se adultos após um rito de passagem que consistia em guerrear contra seus inimigos. Mantinham-se fora da comunidade indígena, ficando expostos aos perigos da natureza e à mercê de outros índios. Isolados, eram forçados a se desenvolverem física e mentalmente. Os sujeitos que retornavam à aldeia, vitoriosos por terem vencido o inimigo, estavam renovados sobre quem eram e qual o seu papel na comunidade.

Os ritos de passagem são manifestados por símbolos criados pelas sociedades e marcam a modificação de papéis que o indivíduo deverá assumir (Rodolpho, 2004). No conceito de ritos de passagem de Van Gennep, há três fases: a separação, a liminaridade e a incorporação (DaMatta, 2000). O rito de passagem dos meninos Tenharim mantém-se com a característica de reclusão e retorno, porém, a mata não é mais a floresta Amazônica, mas, sim, a "grande mata" do homem não índio.

Os entrevistados faziam referências à permissão dos adolescentes para irem à cidade sozinhos ou com os amigos como um marcador de passagem da infância para a vida adulta. Esse distanciamento dos pais representa as duas primeiras fases do rito de passagem da infância para a juventude - a separação e a liminaridade. A ida à cidade, por volta dos 12 anos, significa que o menino vem assumindo sua autonomia enquanto indivíduo, não necessita mais da presença constante dos pais, portanto é responsável por suas atitudes.

Essa relação entre a alcoolização e o rito de passagem também foi encontrada entre os Kaingáng (Souza, Oliveira, Kohatsu, 2003) e os jovens do Alto Rio Negro (Souza, Deslandes, Garnelo, 2010). Entre os jovens dessas etnias, no ato de beber estão embutidos atributos como coragem, valentia e força, remetendo à ideia de masculinidade.

A possibilidade de ir à cidade sem a presença de um parente responsável e o uso da bebida alcoólica fazem parte do novo ritual de passagem da infância para a vida adulta. Nesta fase, é necessário assumir as responsabilidades, portanto ela é liminar, e, no processo de separação e incorporação, pode haver rupturas, e o indivíduo pode passar a consumir a bebida alcoólica de maneira individual, e ser considerado como um membro da comunidade indígena que não assume seu papel de responsabilidade. Declaram que "para não consumir bebida alcoólica é necessário ter uma opinião firme, quem consome a bebida o faz porque quer" (jovem Tenharim). 
A permissividade para o ato de beber não é algo declarado. Mas a dinâmica familiar Tenharim mantém uma característica de emancipação dos rapazes, conseguida anteriormente pela habilidade de caçar, pescar, cultivar a terra e conhecer sobre as questões da natureza. Porém, atualmente, é marcada pelo compromisso com os estudos e autonomia para ir à cidade. A cada membro é aconselhado o que fazer, mas o indivíduo é responsável pelas suas atitudes. Os meninos, ao serem considerados prontos para assumirem responsabilidades, são respeitados como sujeitos. A família passa a interferir se houver extrapolações às regras de condutas, regras estas formuladas com base no consenso familiar. Apesar de pertencerem a uma mesma aldeia, as famílias possuem variações quanto à forma de lidar com os problemas, decisões e tensões.

\section{As regras para o consumo}

Há duas questões importantes a serem discutidas em relação às normas de consumo de bebidas alcoólicas. A primeira é a descrição das regras definidas pelos Tenharim; a segunda está no fato de que certas regras podem perder a validade quando o indivíduo está em estado de embriaguez (Guimarães, Grubits, 2007).

Parece ser consenso, entre os Tenharim, que a bebida alcoólica pode ser utilizada com moderação em dias festivos, como forma de divertimento. Nesses dias festivos, momentos de alegria e descontração são colocados em primeiro plano, diferente dos dias do cotidiano, quando os trabalhos de manutenção e subsistência são prioridade. O que é classificado como moderação não é definido pela quantidade ou tipo de bebidas a serem consumidas, mas, sim, pelo comportamento social assumido. O que torna o uso de álcool um problema é o consumo fora dos dias de festas, e o beber a ponto de ter comportamentos agressivos e provocar brigas dentro da aldeia ou na cidade. Parece claro, também, que é um consenso, entre os Tenharim, que nem todos possuem controle para utilizar o álcool de maneira moderada.

De modo geral, as regras para o consumo são quanto à idade, portanto não sendo permitido às crianças. Também há restrições quanto ao sexo, sendo relacionado a um ato para homens, pois as mulheres são consideradas como criadas na tradição; assim, aos homens, é permitido o alívio do controle social sobre os comportamentos.

Outro fator que está relacionado à normatização quanto ao ato de beber é o estado de saúde atual do individuo. O estado de doença o torna inapto ao consumo do álcool. O estar doente também pode ser influenciado pelo consumo anterior do álcool, conforme relatado pelos mais idosos. Para eles, manter a abstinência ao álcool é uma forma de contribuir para que o estado de doença não se agrave:

“esses jovens não vão conseguir parar de beber depois que envelhecer e vão sentir o peso da bebida depois de velho, isso se antes não receberem o castigo por meio de brigas com os brancos ou entre os próprios parentes. Se eu tivesse seguido os costumes na alimentação, não tivesse gastado dinheiro com bebida não estaria velho e doente como estou hoje". (idoso, líder Tenharim)

Do ponto de vista econômico, o uso do dinheiro para compra de bebidas alcoólicas e o estado de depreciação física e mental para o trabalho e estudo, advindos do consumo, são considerados como um fator negativo. Um dos problemas apontados pela comunidade Tenharim quanto ao uso do álcool está relacionado ao gasto do dinheiro para compra de bebidas, deixando, assim, de prover à família o necessário para a subsistência. Para alguns dos entrevistados, se o Tenharim utiliza o álcool, mas não deixa faltar nada para sua família, os demais parentes não interferem em sua ação.

A influência da alcoolização no desempenho escolar dos jovens também foi apontada. Segundo eles, as bebidas interferem na atenção e aprendizado, tornando-se um efeito negativo para os Tenharim, que valorizam muito a educação, e a maioria dos jovens pretende dar sequência na educação formal visando o nível Superior.

O último aspecto em relação às regras para o consumo é a flexibilidade em avaliar a conduta do alcoolizado. Essa observação foi relatada também entre os Kaingáng, que relevam as ações decorrentes de situações de embriaguez em dias de festa (Souza, Oliveira, Kohatsu, 2003). 
Em dias de trabalho, considerados como impróprios para o consumo de álcool, os indígenas estão inseridos em um universo de regras de condutas: o falar baixo, o andar discreto dos adultos e as expressões comedidas são comportamentos esperados. Em dias cotidianos, não é comum ver grupos de jovens brincando de empurrar, apresentando gestos extravagantes e manifestações de euforia, mas, em dias de comemorações ou à noite, em pequenos grupos, a severidade dessas regras parece ser afrouxada.

Esse fenômeno de se valorizar um mesmo evento de maneira diferente pode ser considerado como remissão e inversão simbólica: "remissão cultural refere-se à maior permissividade social [...] e inversão simbólica diz respeito ao cancelamento da identidade normal e a adoção temporária da identidade de outra pessoa" (Dias, 2008, p.200).

A conotação de não saber o que está fazendo, proveniente da alcoolização, ameniza o rigor das regras de conduta. Porém, se houver necessidade de assumir alguma atitude frente a alguma quebra de regras de conduta, essa decisão cabe à família, e a liderança não interfere de modo direto.

\section{O consumo de bebidas alcoólicas e a relação com a doença}

A questão do alcoolismo em comunidades indígenas é uma problemática que pode ser encontrada em muitas aldeias, porém os estudos que registram esse fato ainda são escassos. Guimarães e Grubits (2007) revisaram as taxas de prevalência de uso de bebidas alcoólicas em comunidades indígenas. Entre os Terena do Mato Grosso do Sul, encontraram uma prevalência de 10,1\%, com índice maior entre os índios acima de 15 anos e os que moravam mais próximo da cidade (Aguiar, Souza, 2001). Entre os Kaingáng no Rio Tibagi (PR), encontraram uma prevalência de $29,9 \%$ de indígenas que fizeram uso de bebidas alcoólicas no último ano, sendo a maior proporção entre homens (Coimbra Junior, Santos, Escobar, 2003).

Mas, existe uma dificuldade em determinar se o uso de bebidas alcoólicas em uma comunidade indígena se configura como um problema para a mesma, devido aos significados sociais e culturais atribuídos ao ato de beber.

Buscando um conceito menos pragmático e evitando, assim, rotular os sujeitos que participaram desta pesquisa, considerou-se o processo de alcoolização como um comportamento apreendido, modelado socialmente e que, eventualmente, traz complicações na área da saúde física e do desempenho social (Marlatt, 2004).

Um dos objetivos deste artigo, ao abordar os envolvidos no processo de alcoolização entre os Tenharim, era definir o consumo como um problema ou, mesmo, como doença, partindo das concepções da própria comunidade.

O conceito sobre o processo saúde-doença como ocorrência de estados de alternância entre equilíbrio e desequilíbrio de fatores pode ser interpretado nas falas dos Tenharim do Marmelos. Os conceitos sobre o uso abusivo de álcool podem ser resumidos de acordo com as frases ditas durante uma conversa na escola: "não bebe porque isso não vai te trazer nada de bom" (Tenharim, 15 anos); "a bebida só estraga a saúde da gente" (Tenharim, 17 anos); "quando você bebe você afasta sua família" (Tenharim, 13 anos); "não pode estudar direito" (Tenharim, 15 anos); "a bebida não leva a nada" (Tenharim, 16 anos).

Para eles, o alcoolista doente é aquele que usa o dinheiro para compra de bebidas mesmo após constituir uma família, perde o respeito e sua posição social na comunidade. Também foi apontada, como característica do individuo doente, a permanência na cidade em um estado de ou'yuga (alcoolização), e ser classificado como aquele que denigre a imagem do grupo frente a outros membros.

Portanto, nas descrições sobre os Tenharim doentes por causa do consumo de bebidas alcoólicas, são apontados prejuízos nos aspectos sociais, econômicos e relacionados à identidade do índio Tenharim. Assim, é possível constatar o caráter social do consumo de bebidas alcoólicas entre os Tenharim, o que aponta para ações de prevenção e tratamento baseadas nas relações do grupo, e não apenas ações individuais. 


\section{Considerações finais}

A interpretação dada, pelos Tenharim, ao consumo abusivo de bebidas alcoólicas está relacionada, sobretudo, à moral, no sentido de boa conduta segundo os preceitos estabelecidos pelo grupo. $O$ consumo socialmente admitido está relacionado a uma fase da juventude masculina, que deve cessar quando o jovem se casa e assume seu novo papel de responsável por sua família. Assim, o ato de consumir bebidas alcoólicas, entre os jovens Tenharim, pode ser relacionado ao rito de passagem da infância para a vida adulta.

Porém, os Tenharim que entraram em contato com as bebidas alcoólicas e as utilizam individualmente são como aqueles que iam para guerra e não conseguiam retornar à comunidade, não venciam os desafios do isolamento - não completavam o rito de passagem da infância para a vida adulta.

A partir da descrição sobre o consumo de bebidas alcoólicas entre os Tenharim, é momento de refletir sobre quais os possíveis caminhos a serem percorridos visando à prevenção e tratamento do problema envolvendo o álcool. Para pensar em qualquer forma de prevenção e tratamento aos alcoolistas considerados doentes, é preciso considerar que o consumo de bebidas alcoólicas é o resultado entre a interação da substância, a disposição psicológica e o contexto do consumo. Da mesma forma, a prevenção e tratamento não são de responsabilidade apenas da comunidade indígena, mas, sim, de todos os órgãos envolvidos na questão indígena.

É inadiável o processo de discussão, entre os profissionais de saúde e os indígenas, para que sejam definidos os papéis de cada um no que se refere a ações relacionadas ao consumo de álcool. É indiscutível que cada setor governamental envolvido nas ações assistenciais considere o significado da alcoolização a partir das referências da cultura Tenharim dos indígenas do rio Marmelos, e não apenas sob a ótica reducionista e individualista do modelo biomédico. Para isso, é importante a elaboração de um instrumento que possa quantificar os problemas relacionados ao álcool, identificando os grupos vulneráveis e o uso racional de recursos de intervenção.

Os próprios Tenharim reconhecem a necessidade de se organizar o atendimento às pessoas com problemas com o álcool, apontadas por eles como doentes. Assim, é necessária a realização de capacitação da equipe multiprofissional que compreenda os aspectos socioculturais, para que atuem no tratamento e prevenção de abuso de bebidas.

A relação entre o consumo de bebidas e a responsabilidade está presente na grande maioria dos relatos dos Tenharim do Marmelos. Mas, é necessário que os próprios Tenharim reflitam sobre algumas questões do seu universo cultural: como se cria responsabilidade? A responsabilidade está relacionada à identidade? A inserção desse novo grupo - os jovens solteiros -, na sociedade indígena, vem ocorrendo de maneira adequada? Os ritos de iniciação estão contribuindo para a constituição de um adulto que mantém sua identidade Tenharim?

Não há, evidentemente, respostas prontas e soluções acabadas. O que se percebe são possíveis caminhos e alternativas que devem ser discutidos e acordados entre todos os atores sociais envolvidos. A colaboração e coesão dos lideres é o ponto inicial para a mobilização de organizações e da comunidade indígena. O trabalho de prevenção e controle das consequências tidas pelos indígenas como negativas não é uma tarefa fácil, e é fragilizada pelo despreparo dos envolvidos em abordarem o tema. Reconhecer a alcoolização como um possível agravo importante à saúde e estabilidade social, compreender as suas diversas interfaces, envolver a comunidade, considerar a sua ocorrência não como individual, mas como parte do todo, são princípios que respeitam as especificidades de cada comunidade, a sua realidade local, e proporcionam o desenvolvimento social sustentável.

\section{Colaboradores}

Os autores trabalharam juntos em todas as etapas da produção do manuscrito. 


\section{Referências}

ACIOLI, M.D. O processo de alcoolização entre os Pankararu: um estudo em etnoepidemiologia. 2002. Tese (Doutorado) - Faculdade de Saúde Coletiva, Universidade Estadual de Campinas, São Paulo. 2002.

AGUIAR, I.; SOUZA, J.A. A ingestão de álcool etílico e enfermidades associadas. In: SEMINÁRIO SOBRE ALCOOLISMO E VULNERABILIDADE ÀS DST/AIDS ENTRE OS POVOS INDÍGENAS DA MACRORREGIÃO SUL, SUDESTE E MATO GROSSO DO SUL, 1997, Londrina. Anais... Brasília, 2001. p.51-60.

COIMBRA JUNIOR, C.E.A.; SANTOS, R.V.; ESCOBAR, A.L. Epidemiologia e saúde dos povos indígenas no Brasil. Rio de Janeiro: Fiocruz, 2003.

COLOMA, C. O processo de alcoolização no contexto das nações indígenas. In: SEMINÁRIO SOBRE ALCOOLISMO E VULNERABILIDADE ÀS DST/AIDS ENTRE OS POVOS INDÍGENAS DA MACRORREGIÃO SUL, SUDESTE E MATO GROSSO DO SUL, 1997, Londrina. Anais... Brasília, 2001. p.127-48.

DAL POZ, J. A etnia como sistema: contato, fricção e identidade no Brasil indígena. Soc. Cult., v.6, n.2, p.177-88, 2003. Disponível em: <http://www.revistas.ufg.br/ index.php/fchf/article/view/918/1122>. Acesso em: 4 ago. 2012.

DAMATTA, R. Individualidade e liminaridade: considerações sobre os ritos de passagem e a modernidade. Mana, v.6, n.1, p.7-29, 2000.

DAVIS, S.H. Vítimas do milagre: o desenvolvimento e os índios do Brasil. Rio de Janeiro: Zahar, 1978.

DIAS, L.F. Usos e abusos de bebidas alcoólicas segundo os povos indígenas do Uaça. In: SOARES, L.E. (Orgs.). Drogas e cultura: novas perspectivas. Salvador: EDUFBA, 2008. p.189-218.

FREITAS, J.G. Os índios Parintintin. J. Soc. Am., v.18, n.1, p.67-73, 1926.

GUIMARÃES, L.A.M.; GRUBITS, S. Alcoolismo e violência em etnias indígenas: uma visão crítica da situação brasileira. Psicol. Soc., v.19, n.1, p.45-51, 2007.

LIMA, T.S. Os dois e seu múltiplo: reflexões sobre o perspectivismo em uma cosmologia Tupi. Mana, v.2, n.2, p.21-47, 1996.

MARLATT, B.C. Debate sobre o artigo de Delma Pessanha Neves. Cad. Saude Publica, v.20, n.1, p.25-60, 2004.

MENENDEZ, E.L. El proceso de alcoholización: revisión crítica de La producción socioantropológica, histórica y biomédica em América Latina. Cuad. Casa Chata, v.57, n.1, p.61-94, 1982

NIMUENDAJÚ, C. Os índios Parintintin do rio Madeira. J. Soc. Am., v.16, n.1, p.201-78, 1924.

PEGGION, E.A. Relações em perpétuo desequilíbrio: a organização dualista dos povos Kagwahiva da Amazônia. 2005. Tese (Doutorado) - Faculdade de Filosofia, Letras e Ciências Humanas, Universidade de São Paulo, São Paulo. 2005.

PEREIRA, P.P.S. O processo de alcoolização entre os Tenharim das aldeias do Rio Marmelos/AM. 2010. Dissertação (Mestrado) - Centro de Ciências e Tecnologia, Universidade Federal de Rondônia, Porto Velho. 2010.

RODOLPHO, A.L. Rituais, ritos de passagem e de iniciação: uma revisão da bibliografia antropológica. Estud. Teol., v.44, n.2, p.138-46, 2004.

SAMPAIO, W. Estudos comparativos sincrônicos entre o Parintintin (Tenharim) e o Uru-eu-uau-uau (amandova): contribuições para uma revisão na classificação das línguas Tupi Kawahib. 1977. Dissertação (Mestrado) - Faculdade de Letras, Universidade Estadual de Campinas, Campinas. 1997. 
SILVA, R.A. Os Tenharim: a pessoa, o corpo e a festa. 2006. Dissertação (Mestrado) Faculdade de Ciências e Letras, Universidade Estadual de São Paulo, Araraquara. 2006.

SOUZA, M.L.P.; DESLANDES, S.F.; GARNELO, L. Modos de vida e modos de beber de jovens indígenas em um contexto de transformação. Cienc. Saude Colet., v.15, n.3, p.709-16, 2010.

SOUZA, M.L.P.; GARNELO, L. Quando, como e o que se bebe: o processo de alcoolização entre populações indígenas do alto Rio Negro. Cad. Saude Publica, v.23, n.7, p.1640-8, 2007.

SOUZA, J.A.; OLIVEIRA, M.; KOHATSU, M. O uso de bebidas alcoólicas nas sociedades indígenas: algumas reflexões sobre os Kaingang da Bacia do Rio Tibagi, Paraná. In: COIMBRA, C.E.; SANTOS, R.V.; ESCOBAR, A.L. (Orgs.). Epidemiologia e saúde dos povos indígenas no Brasil. Rio de Janeiro: Fiocruz, Abrasco, 2003. p.149-67.

SZTUTMAN, R. Cauim, substância e efeito: sobre o consumo de bebidas fermentadas entre os ameríndios. In: SOARES, L.E. (Orgs.). Drogas e cultura: novas perspectivas. Salvador: EDUFBA, 2008. p.219-50.

PEREIRA, P.P.S.; OTT, A.M.T. El proceso de alcoholización entre los tenharim, indígenas de las aldeas del río Marmelos, Amazonas, Brasil. Interface - Comunic., Saude, Educ., v.16, n.43, p.957-66, out./dez. 2012.

El objetivo de este trabajo ha sido el de analizar el proceso de alcoholización en las aldeas de los Marmelos utilizando como método el enfoque antropológico. La forma como los Tenharim toman la bebida alcohólica está relacionada principalmente a un rito del pasaje masculino y con normas bien definidas por las familias con sus mecanismos de protección y control. Fue posible constatar que la alcoholización está siendo investigada por los indígenas, pero con diferencias en la definición de que sea o no un problema, lo que fragmenta las acciones desarrolladas la problemática del alcoholismo. La posición liminar asumida por aquellos que consumen alcohol demuestra la necesidad de fortalecimiento social de la comunidad.

Palabras clave: Salud y sociedad. Alcoholización. Rito de Pasaje. Tenharim. Amazonas. 